\title{
Os rostos das juventudes no ambiente educacional: conflitando a sociedade de consumo líquido-moderna
}

Carlos Marcelo Cavalheiro Félix ${ }^{1}$ Rodrigo Koch ${ }^{2}$

\begin{abstract}
Resumo:
Este texto apresenta as realidades de algumas das juventudes que trafegam pelas vias sociais e, especialmente, pelos espaços educacionais contemporâneos. Em caráter analítico e com perspectiva sociológica, a escrita propõe um olhar sobre o ambiente da educação tendo em vista os fragmentos dos "rostos" das juventudes, nos seus diferentes espaços/tempos no atual construto da contemporaneidade. As bases reflexivas são tecidas sob as lentes sociológicas de Zygmunt Bauman, com base nos conceitos de Modernidade Líquida e da Sociedade de Consumidores cunhados pelo mesmo pensador. Há evidências de certas angústias por parte dos jovens em relação a seu futuro profissional e às descontinuidades e fragmentações identitárias pelas quais deslizam, atrelados ao crescente desinteresse na educação, que ainda segue modelos sólidos e tradicionais diante de uma juventude cada vez mais líquida e com sociabilidades fugazes e efêmeras. Do ambiente líquido-moderno resulta as experiências momentâneas, fluidas e de consumo permanente evidenciando os processos de objetificação da educação e as permanentes buscas identitárias nos diversos contextos das juventudes.
\end{abstract}

\author{
Palavras-chave: \\ Juventude. Educação. Modernidade Líquida. Bauman.
}

\section{The faces of youth in the educational environment: conflicting the modern liquid consumption society}

\begin{abstract}
This text presents the realities of some of the youths that travel through social channels and, especially, through contemporary educational spaces. Analytically and with a sociological perspective, the writing proposes a look at the educational environment in view of the fragments of the "faces" of youths, in their different spaces / times in the current contemporary construct. The reflective bases are woven under the sociological lens of Zygmunt Bauman, based on the concepts of Liquid Modernity and the Society of Consumers coined by the same thinker. There is evidence of certain anxieties on the part of young people in relation to their professional future and the discontinuities and identity fragmentations through which
\end{abstract}

\footnotetext{
1 Mestrando no Programa de Pós-Graduação - Mestrado Profissional de Educação da Universidade Estadual do Rio Grande do Sul (UERGS). E-mail: marcelofelix35@gmail.com. ORCID iD: http://orcid.org/0000-0002-2806-9726.

2 Doutor em Educação. Professor Adjunto da Universidade Estadual do Rio Grande do Sul (UERGS). E-mail: rodrigo-koch@uergs.edu.br. ORCID iD: http://orcid.org/0000-0002-6719-1839.
} 
they slide, linked to the growing disinterest in education, which still follows solid and traditional models in the face of an increasingly liquid and social society. fleeting and ephemeral. The liquid-modern environment results in momentary, fluid and permanent consumption experiences, evidencing the processes of objectification of education and the permanent searches for identity in the different contexts of youths.

Keywords: Youth. Education. Liquid Modernity. Bauman.

\section{Los rostros de los jóvenes en el entorno educativo: en conflicto con la moderna sociedad líquida de consumo}

Resumen: Este texto presenta las realidades de algunos de los jóvenes que transitan por los canales sociales y, especialmente, por los espacios educativos contemporáneos. Analíticamente y con una perspectiva sociológica, la escritura propone una mirada al entorno educativo a la vista de los fragmentos de los "rostros" de los jóvenes, en sus diferentes espacios / tiempos en la construcción contemporánea actual. Las bases reflectantes se tejen bajo la lente sociológica de Zygmunt Bauman, basada en los conceptos de Modernidad Líquida y Sociedad de Consumidores acuñados por el mismo pensador. Se evidencian ciertas ansiedades por parte de los jóvenes en relación a su futuro profesional y las discontinuidades y fragmentaciones identitarias por las que se deslizan, ligadas al creciente desinterés por la educación, que aún sigue modelos sólidos y tradicionales frente a una sociedad cada vez más líquida y social. fugaz y efímero. El ambiente líquido-moderno resulta en experiencias de consumo momentáneas, fluidas y permanentes, evidenciando los procesos de objetivación de la educación y las búsquedas permanentes de identidad en los diferentes contextos de la juventud.

Palabras clave: Juventud. Educación. Modernidad líquida. Bauman.

\section{Introdução}

O presente artigo constitui-se um estudo bibliográfico de caráter analítico e se propõe a socializar pensamentos sobre a educação no contexto das juventudes. As contribuições do sociólogo polonês Zygmunt Bauman e os seus conceitos de "Modernidade Líquida" (BAUMAN, 2001) e "Sociedade de Consumidores" (BAUMAN, 2008b) caracterizam este estudo antecipando as abordagens sobre a educação.

Em uma perspectiva sociológica, foi possível analisar, a partir dos conceitos de Bauman, os rostos das juventudes contemporâneas tendo como "marca" a sociedade de consumo e todos os seus processos de transição do mundo moderno. $\mathrm{Na}$ atual conjuntura, a educação, ainda em seu viés de discursos e ações da sociedade sólida (século XX), não contempla os desejos e os sonhos da juventude que se projeta dentro da sociedade de consumidores, não desejando o papel dos "consumidores falhos" (BAUMAN, 2008b, p. 158), desqualificados e frágeis do mundo contemporâneo.

Em um primeiro momento, o estudo concentra-se na busca da construção identitária da juventude na sociedade de consumo. Em um segundo momento, optou-se por demarcar os rostos das juventudes na sociedade de consumo. No terceiro momento, buscou-se enfatizar a contextualização das juventudes contemporâneas e uma educação que 'conserve' suas raízes. Por fim, em um quarto momento, como se dá o entendimento das juventudes entranhadas em uma educação líquido-moderna.

\section{Construindo identidades jovens na sociedade de consumo}

Quando pensamos a formação de uma sociedade, visualizamos a constituição das raças, das culturas, da economia, da sociabilidade, entre outros. Detemo-nos, na maior parte do tempo, 
em preocupações relacionadas aos sentimentos de adequação de cada sujeito que participa desse ambiente na coletividade.

Em uma estrutura social, encontra-se a dinâmica das faixas etárias que dão rosto a essa construção que se apresenta em permanente movimento e transformações. No ambiente etário, constituímos a infância, a adolescência, a juventude e a vida adulta, essa que nos faz entender o processo do envelhecimento do corpo orgânico, chegando a uma última etapa que se manifesta em ser idoso.

Nos processos que constituem a vida humana, existe o desejo de ser feliz e de completar a própria existência desejando a realização plena da felicidade, e é nisso que se faz o construto humano: almejar a dignidade e a plenitude da vida. Quando nos questionamos a respeito do que é ser feliz, no contexto atual, entendemos como sentimentos de prazer e realização momentâneos e que, para experimentá-lo, não há exigência de tanto esforço. O cenário contemporâneo nos coloca na situação de vivenciarmos o mundo de maneira tão despreocupada com o dia de amanhã que acaba intensificando em nossas atitudes o desejo de insatisfação diante das buscas existenciais. No entanto, ser feliz se torna objeto de satisfação pessoal que alimenta, substancialmente, a sociedade contemporânea em seu processo de individualismo, não permitindo que o sujeito encontre, em suas experiências diárias, sentimentos de coletividade que o conduzam à verdadeira felicidade.

Das etapas que são vivenciadas, o "ser jovem" torna-se a experiência de maior relevância após a infância, pois constitui-se, nos jovens, mecanismos disparadores de relutância e objeções contra os mandos e imposições dos adultos. Para a chegada da juventude, a criança passa pela adolescência que, por vezes, torna-se um período de intensos e tortuosos conflitos que requerem total atenção do adulto responsável por esta vida, que desperta para o pensar e o agir individual, para os desejos orgânicos e, mais intensamente, para as razões de sua existência.

Como se sabe, há dor nas transformações do corpo orgânico e há dor no conhecer-se, na subjetividade enquanto sujeito entranhado no mundo vivido. E são, nas buscas, nos desconfortos e, por vezes, nas ligeiras satisfações que são encontrados o perfil de nossas juventudes. Em uma sociedade de permanentes transformações, identifica-se esse sujeito precisando deparar-se consigo mesmo e fazer acontecer as relações que se projetam no coletivo de suas vivências.

Em contraponto a esse ambiente da formação das juventudes, encontra-se a "sociedade de consumo líquido-moderna" (BAUMAN, 2008b, p. 66) que, no pensar do sociólogo polonês Zygmunt Bauman, concretiza-se nas relações fragmentadas, fluidas e liquidadas (BAUMAN, 2001). No entanto, nessa sociedade se busca, como princípio último, a felicidade, mas protagonizada em um ambiente de consumismo e de superficialidade.

$\mathrm{Na}$ sociedade de consumo, as juventudes estão permanentemente "plugadas" e, para ser mais preciso, "sem fio" (BAUMAN, 2008b, p. 8, grifo do autor). Para Bauman (2008b), isso se constitui a própria exteriorização da vida, significando a necessidade de expor o que é privado e torná-lo público em razão ao atendimento e ao favorecimento daqueles que se constituem consumidores. A busca pela felicidade torna-se uma corrida ao "supermercado do consumo" para encontrar, nas "gondolas capitalistas", a mercadoria utilizável para o momento desejável e que, após a utilização, possa ser descartável sem nenhuma perspectiva de apego. A felicidade se torna um produto dos consumidores, que, de suma, é "instantânea e perpétua" (BAUMAN, 2008b, p. 60).

Nas sociedades pós-modernas, a juventude adquiriu novos contornos, principalmente com o advento de novas ferramentas tecnológicas de comunicação e também de novas concepções familiares. São sujeitos de uma nova geração nascidos e engendrados em uma tecnocultura. Há novas mídias que subvertem completamente às antigas formas de se comunicar com aquisições de culturas internacionais em redes cada vez mais transnacionais. Há um "borramento" de fronteiras em que a juventude se expande e se confunde. Os desejos e sonhos que conduzem os jovens, na sociedade de consumidores, também modificam suas condutas.

Nesse ambiente líquido-moderno, situa-se a constituição das linguagens e da formação dos rostos das juventudes. Uma sociedade de consumidores que perpetuamente busca encontrar-se 
com a felicidade, mas que, ao mesmo tempo, divaga no ambiente fragmentado do esvaziamento de si e de suas buscas mais intensas.

\section{0 rosto das juventudes na sociedade de consumo}

Essa busca de si e da realização plena, na proposta de felicidade, constitui-se o diagnóstico que é alimentado pela leitura baumaniana. Ao se deparar com as relações sociais no ambiente da juventude, Bauman entende o mesmo processo fragmentado e superficial da sociedade de "consumidores" (BAUMAN, 2008b, p. 63). A insegurança gera indivíduos ainda mais sedentos pelo consumo. O autor percebe que, pelo abandono ou a diminuição da importância dos aspectos morais, políticos e sociais, as relações juvenis se projetam em constantes tensionamentos. $\mathrm{Na}$ "Modernidade Líquida" (BAUMAN, 2001), há um descompasso caracterizando-se com um alto índice de insegurança e de ansiedade, fazendo perpetuar a falta de confiança perante o outro e intensificando o individualismo nas relações de sociabilidade que se tornam frágeis e efêmeras.

Para Bauman (2008b), na sociedade de consumo líquido-moderna, o jovem não se revela na sua totalidade, e isso afeta moralmente o indivíduo. A "Modernidade Líquida" (BAUMAN, 2001) apresenta relações fragmentadas em que se pode pensar no rosto das juventudes trocando apressadamente suas roupagens e vestindo de maneira descompassada novas máscaras de acordo com as suas escolhas e com grupos específicos. Nesse ambiente, ainda, estariam as dificuldades para tomar decisões quanto às suas ações de escolha e julgamento, sobretudo a respeito das decisões no que tange o bem e o mal. Nesse sentido, entende-se, na leitura de Bauman (2005), a relação que se pode tecer com o tema das identidades, ou seja, o jovem, desejando experimentar as diferentes identidades que estão a sua disposição, abre-se para vestir as diferentes máscaras que estão disponibilizadas na sociedade de consumo.

No documentário Nunca me sonharam (2017), dirigido por Cacau Rhoden, com roteiro de Tete Cartaxo, André Finotti e Cacau Rodhen, é possível entender os desafios do presente encarados, cotidianamente, por jovens de escolas públicas, de periferia e, as suas expectativas para o futuro. O filme estabelece um diálogo apontando os sonhos de quem vive a realidade do Ensino Médio no Brasil. Nos discursos e falas de estudantes, gestores, professores e especialistas, é possível refletir sobre o valor da educação e os vários rostos fragmentados dessas juventudes que labutam por um espaço nessa sociedade de consumo. Esses rostos jovens e periféricos refletem a grande maioria da população brasileira que resistem ao desinteresse dos gestores públicos, que, nas demandas de sua gestão, não alavancam a educação como um caminho viável de futuras conquistas para o sucesso profissional e relacional dessas juventudes.

Os rostos que se apresentam, ao longo do documentário, anunciam a concepção baumaniana dessas diversas máscaras que precisam ser vestidas pelas juventudes nos diferentes espaços/tempos em que essas se presentificam. Percebe-se, nesses discursos juvenis, a insegurança, o medo, as incertezas que vão "comodificando" e "recomodificando" (BAUMAN, 2008b, p. 82) relações estabelecidas no ambiente da sociedade de consumo líquido-moderna. As expectativas de um futuro grandioso não desaparecem de seus discursos, mas a realidade nua e crua está muito presente em suas falas, em suas posturas e em suas compreensões quanto às relações sociais, culturais e econômicas que ali se estabelecem.

Os discursos que ecoam na abertura do filme revelam o contexto em que essas culturas juvenis se entrelaçam com a sociedade de consumo: "Eu quero ser uma adulta-criança-jovem-adolescente"; "Eu não queria ser jovem não. Queria passar direto para a fase adulta"; "Eu sou um defeito de fábrica"; "A única certeza que tenho é que um dia vou morrer"; "A partir do momento em que o sonho foi tirado de mim, aí eu desisti dele também"; "Eu quero que você saia do seu mundinho e cresça" (NUNCA..., 2017). As cenas refletem olhares distantes e angustiados diante de sua própria 
existência. As frases curtas se tornam estendidas diante da percepção e do sentimento de cada jovem que as pronunciam. Os textos ganham contornos de atos dialógicos à medida que, ao longo do filme, os jovens expõem suas preocupações com o mundo percebido e com o seu futuro. Essas juventudes veem na educação uma possibilidade de vencer os obstáculos da pobreza e de sair da condição social periférica à qual são submetidos cotidianamente.

No contexto líquido-moderno, vivido pelas juventudes, torna-se possível o termo ambivalência, significando, para Bauman (1999), que ao passo que o jovem procura a segurança e a estabilidade, sabe que está diante de inúmeras possibilidades que poderão conduzi-lo à ruína de si mesmos e de seus próprios sonhos. Nesse ambiente da "Modernidade Líquida" (BAUMAN, 2001), o autor parece reconhecer que as relações que se estabelecem a partir das identidades se tornam "agoristas" (BAUMAN, 2008b, p. 50), impossibilitando às juventudes buscas mais intensas e maturadas de sua própria existência. Porque as culturas juvenis habitam a sociedade de consumo, refletem as práticas dos consumidores, portanto suas identidades são marcadas por aspectos imediatistas e fragmentados. Suas buscas são apressadas e sem sedimentação, transpondo à sociedade contemporânea experiências fluidas e de liquidez permanente.

O espaço que esta nova configuração da juventude passou a ocupar na sociedade ocidental capitalista pode ficar mais claro quando analisamos que já surgiu há muito tempo e, com ênfase maior nas últimas décadas, um novo grupo de consumidores com produtos especialmente pensados para eles. O entusiasmo faz deles cobaias involuntárias para a sociedade de consumo, emergente durante as primeiras décadas do século XX e consolidada no século XXI. Mais que trabalhadores satisfeitos e seguros se convoca os jovens a serem subcontratados, empregados temporários e buscadores de oportunidades eventuais. Portadores de diplomas colocam-nos de lado, junto a lembranças de família, aceitando empregos que não exigem muita qualificação, na promessa de engordar os magros salários com gorjetas de clientes. "Alguns observadores franceses estão se apressando em anunciar a chegada da geração 'Ni-Ni' (nem emprego, nem educação) - talvez a primeira geração realmente global" (BAUMAN, 2013, p. 41). A circunstância, é cada vez mais comum entre os jovens brasileiros. Esses jovens são vítimas de um 'desalento estrutural', ou seja, são pessoas que desistiram de procurar trabalho, porque não têm quase nenhuma qualificação e, tampouco, querem voltar a estudar porque não se sentem atraídas pela escola. É um grupo geracional que não reconhece seu passado e não sabe seu futuro, e para o qual o modelo de triunfo social é ser um ex-big brother.

Diante de permanentes mudanças e da inconstância de vida, a sociedade de consumo projeta as juventudes para experiências fluidas, sem solidez e descartáveis. O outro é visto como um objeto de uso. À medida do término do encantamento do produto/mercadoria, torna-se possível o descarte e a substituição por algo novo. Toda a perspectiva de solidez do século XX, para as juventudes, entra em crise transparecendo a fragilidade das relações e das estruturas. Hoje não há mais a perspectiva do Estado protetor, onipresente e, nessa mesma esteira, percorrem as grandes instituições, de modo especial, as instituições educacionais.

Esse consumidor líquido-moderno apressado, em frente ao seu computador ou ao aparelho celular de última geração, pode ligeiramente se movimentar e apropriar-se de informações aos quais as culturas juvenis anteriores não tiveram o mesmo acesso e oportunidade, ou, se tiveram, o processo ocorreu com maior lentidão. As facilidades oferecidas pela sociedade de consumo ultrapassam todas as projeções da modernidade sólida.

A descartabilidade com que se constata as ações da "cultura agorista" provoca reações de distanciamento das relações maturadas e duradouras.

Quando Bauman pensa a relação dos jovens de hoje (geração y) e o seu vínculo com as formas de trabalho, entende que "a última coisa de que gostariam é de um emprego com estabilidade eterna" (BAUMAN, 2010, p. 61). As relações com o projeto de vida a longo prazo estão distantes dos consumidores jovens da sociedade de consumo líquido-moderna. Com 
o documentário Nunca me sonharam (2017), pode-se perceber o desejo de algo, o anseio por uma vida social e econômica que os retire da situação de pobreza e de periferia. E, por quê? Porque, nessa sociedade de consumo, não há lugar para os "consumidores falhos" (BAUMAN, 2008b, p. 158). Ser um consumidor falho é permanecer na periferia, na subclasse. Nesse sentido, o documentário traduz o desejo desses novos consumidores que ensejam não uma vida de "homens-sanduíches" (BAUMAN, 2008b, p. 158), mas uma existência profícua na sociedade de consumidores. Nos discursos dos jovens, percebe-se, potencialmente, o desejo de fazer parte dessa sociedade contemporânea, que exige dos consumidores habilidades e competências para jogar o jogo do consumir permanente.

No entanto, uma leitura da juventude, sob a ótica das reflexões baumaniana, não pode se desfazer de duas características principais que devem ser consideradas: a do consumo e a da ambivalência. Os sujeitos jovens passam a ser reconhecidos socialmente não mais por aquilo que são ou pelo que produziram, mas pelo que eles consomem ou são capazes de consumir. Analisando a relação do consumo, no ambiente das juventudes, Bauman (2010, p. 55) diz que,

na torrente de bens que se adquirem depressa, se abandonam e jogam fora mais rápido ainda, dificilmente alguma coisa sobressai como 'um bem caro ao coração' - e se faz, não é por muito tempo. Importante é sempre guardar o estilo, não a parafernália de acessórios que o compõem; e esse estilo exige que os acessórios se sucedam uns aos outros em velocidade cada vez mais acelerada.

Na perspectiva da sociedade de consumo, esses impulsos, quase sempre subsidiados pelo ato de consumir, pela oferta de diferentes identidades, uso diversificado de máscaras e das relações de sociabilidade fluidas, fragmentadas e superficiais, desembocam na questão da ambivalência. Para Bauman (1999), a ambivalência privilegia os juízos contraditórios sobre uma mesma questão, que pode ser associada ao ato de consumir e às relações coletivas. Para as juventudes contemporâneas, exige-se o ato de apropriação e de abandono imediato e apressado da mercadoria que se pode consumir. Nesse sentido, não há tempo para permanecer estagnado nas coisas do coração, mas abandonar todo e qualquer sentimento que o conduza ao apego de si ou de outros.

\section{Para as juventudes contemporâneas: uma educação que "conserve" suas raízes}

Apesar das inúmeras transformações sociais nas últimas décadas, principalmente desde os anos 1990 e, ainda, na entrada do novo milênio, algumas instituições continuam sendo centrais e de referência na vida das sociedades modernas e, agora, em passagem tardia para pós-modernas. Talvez, o melhor exemplo disso seja a escola que, mesmo em tempos "líquidos" e "leves" - quando os alunos são educados não mais somente pelos professores, mas também pelas mais variadas mídias e artefatos culturais -, continua ocupando o espaço formal da educação. É ponto de consenso e se convencionou e regulamentou, desde o século XIX, que qualquer criança ou jovem tenha o direito - e por que não, também o dever - de frequentar a escola para adquirir conhecimento e ser preparado para e pela sociedade na qual está inserido. Aqueles que estão fora desta condição, são vistos como "os outros", os excluídos que vivem em situação "anormal". No entanto, a sala de aula contemporânea se vê ameaçada pela fluidez e instantaneidade dos artefatos pós-modernos e, é encarada muitas vezes como um espaço de lazer ou tortura. O próprio método de aprendizagem se transformou. Bauman (2013) faz analogia entre mísseis balísticos (aprendizagem moderna) e mísseis inteligentes (aprendizagem pós-moderna) para caracterizar a condição contemporânea da educação dos jovens, afirmando que o talento em aprender depressa está diretamente vinculado à capacidade de esquecer instantaneamente o que foi aprendido antes. 
Partilhar de experiências que nos levam a questionar com veemência o modelo de educação que se projeta na prática atual, e o que nos instiga, conscientemente, para a elaboração de um projeto real de educação que promova a liberdade do ser, constitui-se um caminho árduo e de muitos obstáculos. No documentário Escolarizando o mundo: o último fardo do homem branco (2010), uma coprodução americana e indiana dirigido e editado por Carol Black, refletimos a marca da presença ocidental que dita as regras para a educação. De maneira impositiva, a cultura branca globalizada e capitalista se sobrepõe às diversas culturas e identidades nos diferentes continentes, exterminando suas raízes identitárias e apagando de suas mentes os princípios fundacionais de sua existência. $\mathrm{O}$ acento impositivo tem o seu teor negativo e intencional. A cultura do lugar não importa: pode morrer. A intenção está em homogeneizar as culturas e as identidades destruindo os processos civilizatórios naturais como sujeição do mais fraco aos mandos do mais forte.

É notório, através das paisagens e recortes de falas do senso comum dessas culturas e identidades, o quanto "conservar os rituais culturais" do lugar e da vida cotidiana ajuda no processo da construção da identidade de um povo, de uma nação. Quando nos deparamos com o processo de escolarização imposto pela "cultura branca e ocidental" que, sem se interrogar, transita em meio a outras culturas e impõe seu formato de ensino é possível retornar a Bauman no seu conceito de "sociedade de consumo líquido-moderna" (BAUMAN, 2008b, p. 97), para dizer dessa prática consumista e depredatória imposta pela cultura globalizada e capitalista. Cultura essa que se mantém despreocupada com o "fincamento" e o enraizamento das diversas identidades. Um olhar que se constitui de cima para baixo usando a verticalidade do colonizador, que não se propõe à abertura e ao diálogo para encontrar novos sentidos a partir do que já existe nas diferentes culturas.

Viver sob os aspectos da cultura globalizada, capitalista e branca, que marca os processos de identidade, na atualidade, nos faz perceber o quanto a negação do olhar sobre as diferentes realidades se tornou a prática dos processos educacionais da atualidade. Vivemos sob a tensão do que o sistema (governo) impõe para as vivências cotidianas do discurso e práticas educacionais e, ao mesmo tempo, sob o olhar das experiências trazidas, diariamente, pelos alunos que recebemos dentro dos muros de nossas escolas. O sistema atual impõe a esses jovens que deixem do lado de fora dos muros a sua vida real, os seus anseios naturais, a sua existência. Dentro dos muros da escola só é permitido um caminho: deixar morrer sua "realidade natural" para assumir o "impositivo" desejo de preparação para o mercado de trabalho. Os sentidos da escola para os jovens contemporâneos parecem estar relacionados somente à necessidade de certificação e do consequente desejo de mobilidade e transição social na busca permanente de oportunidades frágeis e postos de trabalho transitórios. No entanto, o que se percebe é que, para as juventudes, o espaço escolar está muito mais próximo de um local para trocas de sociabilidades e práticas culturais do que para o sentido capitalista e globalizado do mercado.

Com Bauman (2008a), podemos refletir o "marco" da educação imposta pela cultura branca e ocidental. A educação para o mercado de trabalho é, sem dúvida alguma, o que a ocidentalidade branca, globalizada e capitalista, impõe como condição de sobrevivência para o século XXI. Mas, aqui nos cabe perguntar: é fato que esse tipo de prática educacional prepara os sujeitos para os contextos atuais? Na leitura do documentário, é notória a necessidade com que a "cultura branca" precisa embasar a aculturação dos povos de "cultura marrom". De fato, é preciso "matar" uma cultura para fazer emergir a outra? Quando pensamos os processos educacionais impostos pelo sistema podemos perceber a brutalidade da mão "opressora" que destrói, sem pesar, os processos educacionais, culturais e identitários dos diferentes povos e locais.

No olhar baumaniano (2008a, p. 163), o ambiente da crise educacional é marcado pelo sentimento de fluidez. O que meticulosamente a modernidade busca fazer, a pós-modernidade avança em rumos diferentes colocando em "suspensão" a herança das antigas instituições e filosofias herdadas. Para a leitura de Bauman (2008a), as fórmulas tradicionais usadas no seu campo de atuação corrompem a educação. Elas se comportam como fábricas para suprir os desejos de uma 
elite educada, porém não respondem mais aos anseios contemporâneos. Seu comportamento está em estruturar, junto aos profissionais da educação, teorias e planejamentos que estabeleçam currículos, e que esses sejam aplicados para a solidez do mercado capitalista. Para o autor, "o principal papel do ambiente educacional está em repensar e rearticular seus métodos no mundo pós-moderno, que vê com grande suspeita os valores da modernidade que ele ainda defende" (BAUMAN, 2008a, p. 172). Segundo Bauman (2008a, p. 178), é preciso "buscar por processos abertos, abrindo possibilidades para sugerir e não impor resultados que resultem em limitar sua estrutura".

Uma educação "gradeada" em sistemas fechados e impositivos, provavelmente, não produzirá efeitos na sociedade contemporânea. O que de fato percebemos, no ambiente da educação, são mecanismos de "poda" e de "morte" que estão apostos para destruir as culturas e as identidades. Nesse sentido, está a "cultura marrom" que no seu fazer cotidiano, demonstra maior lucidez no processo, quando se preocupa em questionar a "cultura branca" quanto aos seus processos que intensificam a "cultura de morte" a partir da educação de seus filhos. Em nome da maquinaria dos processos educacionais, não se pode matar a cultura do outro, mas promover práticas de "ensinagem" e aprendizagem que motivem a permanência nas raízes fundacionais.

\section{As juventudes entranhadas em uma educação líquido-moderna}

Na visão baumaniana, o construto sobre a educação e as juventudes está sob o alicerce da homogeneidade da sociedade de consumo. No ambiente das relações, os sujeitos são intensamente instigados a comprar e gastar o que têm e o que não têm para saciar todas as fantasias, ansiedades, dores e frustrações. Nessa sociedade de consumidores, a ânsia consumista absorve o setor mais almejado pelos mercados que são as juventudes.

Na perspectiva do mercado consumista, esse grupo social se apresenta com potencialidades maiores de gerar novas frentes de exploração, graças ao constante adestramento ou treinamento de práticas de consumo oriundas das novas mídias e, em especial, das redes sociais e das ferramentas tecnológicas, que superabundam no ideal capitalista. A construção das amizades ou de outros laços sociais prefiguram o sentimento "agorista" (BAUMAN, 2008b, p. 50) de descartabilidade e, posteriormente, de acordo com os anseios momentâneos, torna-se a prática que o mercado visa para o nosso consumo cotidiano.

O modelo atual da educação vive as suas crises e evidências paradigmáticas relacionadas, mais profundamente, ao campo do sistema capitalista. Quando Bauman (2013) reflete a crise da educação contemporânea, entende que essa se torna muito peculiar porque, provavelmente, pela primeira vez na história moderna, percebemos que as diferenças entre os seres humanos e a falta de um modelo universal vieram para ficar. Para o autor, a "Modernidade Líquida" (BAUMAN, 2001) representa, sobretudo, o rasgamento da máscara das ilusões e o reconhecimento de certas pretensões como falsas e de certos objetivos como inatingíveis.

Essa ruptura também atinge a destituição dos alicerces de estabilidade do discurso pedagógico que sustentam as práticas educacionais escolares, sejam elas consideradas progressistas ou conservadoras. Bauman (1999, p. 11) atenua para uma "ambivalência" em que os discursos pedagógicos se tornam inadequados e impossibilitam alicerces estáveis, sob condições de reconhecida contingência. Com isso, o que o autor apresenta para a educação no século XXI é um ambiente de desordem e caos em que se constitui a metáfora da "liquidez" (BAUMAN, 2001, p. 8).

Nessa perspectiva, Bauman (2013, p. 22) entende que a solidez da modernidade - século XIX e XX - já não determina o atual momento. O que constituía o ambiente da modernidade era a solidez das crenças na ciência racionalista, que impulsionava a duração de todas as coisas, exceto a vida moral. No ambiente da "Modernidade Líquida" (BAUMAN, 2001), o autor afirma que as crenças da modernidade não dão conta de explicar as relações e, por isso, todas entram 
em suspensão. As fórmulas e as normas já não reproduzem as necessidades atuais. Tudo se torna transitório universalmente em um ambiente de liquidez instantânea com prazos de validade.

Os elementos da "Modernidade Líquida" (BAUMAN 2001) vão estabelecendo os novos contextos que determinam o novo universo das relações. Para Bauman (2013), isso constitui "o dilema da 'descontinuidade' na 'continuidade', significando o movimento fluído, constante e obsessivo em que se dão as relações atuais” (BAUMAN, 2013, p. 83). Na concepção baumaniana, "a pós-modernidade é a modernidade reconciliada com sua própria impossibilidade - e decidida, por bem ou por mal, a viver com ela" (BAUMAN, 1999, p. 110). Nesse intento, o autor afirma que estamos diante de um mundo fluído e em processo permanente de liquefação em que se deve evitar a transformação das coisas em hábitos, um mundo da cultura do desengajamento, da descontinuidade e do esquecimento.

Para Bauman (2008b), a contemporaneidade vive o ato de consumir e descartar, enfraquecendo e deteriorando os vínculos humanos. Esses acontecimentos, reafirmados por valores capitalistas, refletem suas concepções no tocante à educação. O que geralmente percebemos é uma educação voltada para o mercado de trabalho com incentivos capitalistas, vinculada cada vez mais ao ato de consumir. Esse cenário dificulta a escolha de teorias que possam ancorar as práticas docentes.

Dois documentários dirigidos por João Jardim - Pro dia nascer Feliz (2006) e Atravessa a Vida (2020) -, desvelam esses acontecimentos atuais que permeiam o contexto das juventudes, entrelaçando as culturas capitalistas e líquido-modernas no seio da educação brasileira. O primeiro aborda o sistema educacional brasileiro, descrevendo realidades escolares e diferentes contextos sociais, econômicos e culturais a partir de diversos olhares sobre as realidades que constituem a estrutura educacional, seja do ponto de vista da instituição, do aluno, do professor e da família. Propõe, ainda, demonstrar o abismo existente entre as escolas públicas e privadas e a relação do adolescente com a escola focando a desigualdade social e a banalização da violência. No segundo, o diretor acompanha três meses de preparação dos alunos do terceiro ano do Centro de Excelência Dr. Milton Dortas, em Simão Dias, Sergipe, para expor e relatar a situação de como se dá a preparação para o ENEM e quais expectativas têm para o futuro. Segundo o diretor, esses jovens, na sua maioria, foram criados e educados somente por suas mães. Os dois documentários abordam temas muito relevantes e amplos, como a percepção dos jovens sobre a política nacional, as opiniões sobre o aborto, a pena de morte, a educação brasileira, as perspectivas para o futuro, ditadura militar, a violência e a periferia.

É possível perceber que, nesses ambientes educacionais e sociais, contrastados com a sociedade de consumo, as histórias de estudantes em diferentes escolas e estados do Brasil se concretizam em uma radiografia do ensino, mas também das diferenças sociais deste país continental. Escolas urbanas que abrigam a elite que tudo tem. Escolas públicas em pequenas cidades do interior onde faltam estruturas físicas de qualidade e, por vezes, o material humano para dar assistência à formação desses jovens. A busca dos sonhos e anseios, dos medos, das incertezas e das inseguranças marcam os discursos dessas juventudes. Os dois documentários tecem um recorte verdadeiro da realidade e das dificuldades da educação brasileira. Uma proposta de educação que não contempla a necessidade de mudanças e transformações para que essas juventudes possam reconhecer-se parte daquela sociedade. Uma educação que desprivilegia os "consumidores falhos" (BAUMAN, 2008b, p. 158) que não conseguem competir com a abundância oferecida na sociedade dos consumidores.

Os prognósticos de Bauman (2008b) se agravam quando entende que, na sociedade dos consumidores, cresce o número dos 'desqualificados' que não podem atingir os padrões de normalidade difundidos pelo mercado capitalista, cuja parte expressiva da juventude se encontra nesse segmento. Um dos fatores que elevam os índices da marginalização da juventude é a desigualdade nas oportunidades educacionais, em que o Estado se desobriga das responsabilidades de um ensino de qualidade, aportando suas expectativas na iniciativa privada. A prática dos "consumidores" (BAUMAN, 2008b) estabelece que a própria educação, como "produto" à venda nas gondolas de um supermercado, 
torna-se um objeto com descartabilidade total. Nisso, a educação se torna uma mercadoria para ser consumida e descartada na medida das imposições do mercado capitalista. Para os "consumidores" líquido-modernos, é preciso desenvolver o talento de aprender depressa e a capacidade de esquecer instantaneamente o que foi aprendido, pois as informações envelhecem rapidamente, e o conhecimento torna-se eminentemente descartável. O que se mantém na "Modernidade Líquida" (BAUMAN, 2001) é a não-garantia de que a educação se fará duradoura, ou que se obterá clareza nos conhecimentos. O que permanece é a ausência de certezas no campo do conhecimento.

Em uma entrevista com Alba Porcheddu, em 2009, sobre educação, Bauman retorna as ideias e vivências do mundo líquido-moderno para afirmar "que a educação e a aprendizagem, para serem úteis, devem ser contínuas e durar toda a vida, sendo impensáveis de qualquer outro modo que não seja aquele contínuo e perpetuamente incompleto" (PORCHEDDU, 2009, p. 680). Na perspectiva do autor, assim como o mundo capitalista desenvolve as suas conexões, a educação se constitui, no mundo líquido-moderno, não unitária, homogênea e universalmente aceita e praticada. Para Bauman, "não devemos nos adaptar ao ritmo desenfreado das mudanças do mundo, mas, sobretudo, tornar o mundo em uma contínua e rápida mudança, mais hospitaleiro para a humanidade" (PORCHEDDU, 2009, p. 680).

No contexto da "Modernidade Líquida" (BAUMAN, 2001), a educação torna-se um objeto de consumo que detém valor de mercado e pode ser adquirido por qualquer sujeito que detenha o poder de comprá-la. Sendo um valor de consumo e objeto de elevado valor de mercado, a educação se torna um elemento importante para a dinâmica econômica da sociedade vigente. Em sua concepção, ela se apresenta inacabada e em processo contínuo, pois não tem um ponto de chegada em vista de sua construção.

O processo de formação continuada dos docentes se apresenta conforme a necessidade do cotidiano escolar ou mesmo das políticas vivenciadas. Mediante esse processo, o fim não importa, porém, a sua realização contínua. Nesse sentido, perguntamo-nos: qual a razão de estudar? Para que, afinal, eu me formo? Na perspectiva da sociedade de "consumidores", a formação acontece segundo a lógica do mercado de trabalho, que impõe a certificação e a formação continuada como critério de utilização do consumismo.

O mundo contemporâneo investe na educação trazendo, para dentro da escola, as marcas do individualismo e do consumismo. Em suas relações cotidianas, a escola distribui, por meio das práticas e discursos, a necessidade de empreender e ser proativo conforme as necessidades do mundo capitalista. É possível perceber uma formação que reproduz os valores da "sociedade de consumo" (BAUMAN, 2008b, p. 63), deixando para um segundo plano os questionamentos com relação a esse processo. No ambiente líquido-moderno, a educação passa a desenvolver mecanismos que projetam o ser humano no caminho do individualismo e não da coletividade. Nesse sentido, torna-se quase uma utopia os sentimentos de pertencimento ao lugar e, por consequência, perde-se a vinculação da amizade e da solidariedade.

Nas considerações de Bauman (2008b), a cultura da sociedade de consumo líquido-moderna não estimula a prática da aprendizagem e da acumulação de conhecimento. O que o autor observa é que ela incentiva a rápida descartabilidade, o desengajamento, a descontinuidade e o esquecimento, sustentado em favor da frenética vontade de consumir. Tendo a consciência de não impor convencimento algum sobre essas questões, o sociólogo acredita que, para o futuro, apresenta-se o desenvolvimento de uma 'revolução cultural' que desorganize e reordene tal identidade consumista. Para tanto, o sistema educacional, apesar de limitado e cada vez mais submetido à lógica do capitalismo e da sociedade dos consumidores, pode ser uma das principais molas propulsoras dessas transformações.

No entendimento de Bauman (PORCHEDDU, 2009), é necessário o constante fomento à resistência dos sistemas impostos para a educação. Cabe intensificar o espírito crítico na tentativa de alavancar os processos educacionais. Para o autor, torna-se possível aliar a força da resistência e do 
espírito de criticidade à crença de que a juventude possui capacidade criativa e de apropriação de novas ideias para estabelecer as peças-chave para a construção dessa nova "revolução cultural".

\section{Considerações finais}

Este estudo abordou o tema das juventudes e da educação, tendo como objeto investigativo os rostos das juventudes no ambiente educacional, conflitando a sociedade de consumo líquido-moderna. Compreende uma abordagem de cunho sociológico, amparando-se nos conceitos de "Modernidade Líquida" e "Sociedade de Consumidores", do sociólogo polonês Zygmunt Bauman. O cenário da educação entra em conflito com os rostos das juventudes contemporâneas intensificando o desejo capitalista e globalizado. Essa sociedade de consumidores, presentificada nos jovens, requer condições de consumo permanente fechando-se para rostos "desqualificados" e da "subclasse".

$\mathrm{Na}$ abordagem do texto, é possível constatar que: a) as juventudes estão entranhadas na sociedade de consumo e que se tornam objeto consumível e descartável seguindo os princípios da "Modernidade Líquida" (BAUMAN, 2001); b) no ambiente líquido-moderno, a educação se tona um instrumento do capitalismo e do mundo globalizado; c) os jovens não abriram mão de seus sonhos e lutam por mudanças sociais e econômicas no ambiente em que vivem; d) a educação superficial e periférica do mundo líquido-moderno conflita com as buscas de transformação e transição dos jovens contemporâneos; e) a construção do conhecimento, superando as informações apressadas, na sociedade de consumidores, enseja uma revolução cultural de pensamento e ação social. Nessa perspectiva, os rostos das juventudes contemporâneas permanecem fragmentadas, vestindo-se de roupagens e máscaras que descaracterizam seus sonhos e a busca pela real felicidade. A educação permanece nos modelos sólidos e tradicionais em desalinhamento com as juventudes que são marcadas pela sociedade de consumo numa perspectiva fugaz e efêmera.

\section{Referências}

ATRAVESSA a Vida. Direção: João Jardim. Sergipe: Copacabana Filmes; Globo Filmes, 2020. Disponível em: https://www.youtube.com/results?search_query=document\%C3\%A1rio+atravessa+a+vida. Acesso em: 13 nov. 2020.

BAUMAN, Zygmunt. Modernidade e ambivalência. Tradução: Marcus Penchel. Rio de Janeiro: Zahar, 1999.

BAUMAN, Zygmunt. Modernidade Líquida. Tradução: Plínio Dentzien. Rio de Janeiro: Zahar, 2001.

BAUMAN, Zygmunt. Identidade: entrevistas a Benedetto Vecchi. Tradução: Carlos Alberto Medeiros. Rio de Janeiro: Jorge Zahar, 2005.

BAUMAN, Zygmunt. A sociedade individualizada: vidas contadas e histórias vividas. Rio de Janeiro: Zahar, 2008a.

BAUMAN, Zygmunt. Vida para o consumo: a transformação das pessoas em mercadoria. Tradução: Carlos Alberto Medeiros. Rio de Janeiro: Zahar, 2008b.

BAUMAN, Zygmunt. 44 cartas do mundo líquido moderno. Rio de Janeiro: Jorge Zahar, 2010.

BAUMAN, Zygmunt. Sobre educação e juventude: conversas com Ricardo Mazzeo. Rio de Janeiro: Zahar, 2013.

ESCOLARIZANDO o Mundo: O Último Fardo do Homem Branco. Direção: Carol Black. Produção: Neal Marlens, Jim Hurst e Mark Grossan. Ladaque: Lost People Films, 2010. Título original: Schooling the World: The White Man's Last Burden. Disponível em: https://www.youtube.com/watch?v=XeT-JlvS8wE. Acesso em: 19 set. 2020.

NUNCA me sonharam. Direção: Cacau Roden. Roteiro: Tete Cartaxo, André Finotti e Cacau Rodhen. Brasil: Maria Farinha Filmes, 2017. Disponível em: https://www.youtube.com/results?search_query=document\%C3\%A1rio+nunca+me+sonharam+youtube. Acesso em: 16 nov. 2020. 
PORCHEDDU, Alba. Entrevista sobre a educação: desafios pedagógicos e modernidade líquida. Entrevistado: Zygmunt Bauman. Cadernos de Pesquisa, São Paulo, v. 39, n. 137, p. 661-684, maio/ago 2009. Tradução: Neide Luzia de Rezende, Marcello Bulgarelli.

PRO DIA nascer feliz. Direção: João Jardim. Produção: Flávio R. Tambellini. Brasil: Copacabana Filmes, 2006. Disponível em: https://www.youtube.com/results?search_query=document\%C3\%A1rio+pro+dia+nascer+feliz. Acesso em: 14 nov. 2020.

Data de submissão: 07/01/2021

Data de aceite: $15 / 01 / 2021$ 